Taking the view that there must be either a kink at the original seat of hernial strangulation or bands of adhesion or both together I opened the abdomen (on Oct. 19th) by an incision along the outer border of the right rectus muscle. It was at once seen that the intestine was matted together round the knuckle of intestine originally in the hernia by many firm adhesions which fixed it in the position to which it had been returned. It was sharply kinked and soldered up into one mass in this position. The adhesions spread for a considerable distance around and one loop a foot from the kink was fixed by a strong band out of sight on the left side of the abdomen. To reach this I had partially to divide the right rectus muscle transversely from without and then only with the greatest difficulty could this band, which was about as thick as a goosequill be separated from the bowel. An attempt was now made to undo the kink but it only resulted in opening the damaged, softened intestine. I therefore closed the intestine above and below all the portions involved in the matted adhesions in the Doyen's forceps and removed the whole mass, cutting the mesentery close to the intestinal attachment. The cut ends of the intestine were now united end to end in the usual way by two rows of fine silk sutures-a deep and a superficial. The hole in the mesentery was also closed and the area of operation was dried out. The transverse cut in the rectus muscle was stitched up with buried sutures, as also was the upper part of the vertical incision. The lower part of the latter was left open to hold a gauze drain for a few days.

The patient bore the operation very well and convalescence was uneventful, except for a slight rise of temperature for the first few days. until the gauze drain had been removed. She had been rather collapsed on the evening of operation, but she recovered rapidly under saline injections under the skin and rectal injections of brandy-and-water. The bowels acted well on the fifth day naturally and almost daily subsequently. The superficial wound healed per primam except at the lower angle where the drainage gauze lay and at the upper angle where there was some serum pent up in the fat. She was fed by the mouth with small quantities of albumin water from the second day onwards and was soon taking solids. At no time was there any trace of fæces in the drainage from the lower angle of the wound. The patient returned home to Cornwall just before Christmas quite well.

The following is the surgical registrar's description of the parts removed:-

The length of the small intestine remored was ascertained by the curator to be 37 inches. The upper seven inches above the obstruction was hypertrophied and dilated. The chief narrowing consisted of an atrophied fibrous shrinking of the bowel, reducing its lumen to the size of a cedar pencil, at one spot about one-third of an inch in length. size of a cedar pencil, at one spot about one-third of an inch in length. Immediately around this and for eight inches below the bowel is
irregularly distorted by adhesions which matted it together during its irregularly distorted by adhesions which matted it together during its
stay in the abdomen. Towards the lower end there are several more stay in the abdomen. Towards the low
adhesions which do not distort the gut.

This case must, I think, have a certain interest for all surgeons, whether in general or in special practice. It illustrates the need of an early operation in all cases of strangulated hernia. It also shows that although a relatively early operation may be done and be immediately as successful as any such measure can be all dangers are not necessarily thereby prevented. In this case we know certainly the moment at which the strangulation began We know that the herniotomy was performed about 18 hours later. We know that the bowel although discoloured showed active circulation and no lymph upon its surface. And yet, though the recovery was perfect from the reduction and the radical cure, a most serious condition of things was left in the abdomen which led to two severe and nearly fatal attacks of intestinal obstruction and ultimately required one of the most serious operations in surgery. The first herniotomy was quickly over and it involved no great exposure of the gut to manipulation. It was such as one constantly does without misgiving, and yet the changes induced in the bowel by the strangulation were very grave. Fortunately, the subsequent attacks of obstruction were under the care of two highly skilful general practifioners who not only treated them with the utmost judgment but also recognised with promptness the need of subsequent surgical interference. It is also fortunate that now in enterectomy we have a means of remedying such conditions as result from kinks and adhesions without such severe risks as were formerly bound up with excision of the intestine.

Harley-street, $w$.

\section{PRELIMINARY NOTE ON THE DIRECTION OF THE AIR CURRENTS IN NASAL RESPIRATION.}

By CHARLES A. PARKER, F.R.C.S. EDTr.

SURGEON TO THE HOSPITAL FOR DISFASES OF THE THROAT, GOLDEN-SQUARE.

OBSERVATIONS were carried out in order to determine the exact course which the air takes within the nose during nasal inspiration and expiration. The method employed for inspiration was that of impregnating the air with lycopodium by means of an insufflator held about eight inches from the nose both during quiet and forcible inspiration, and then noticing the disposition of the powder within the nasal cavities. For expiration the gentle, and afterwards the forcible, exhalation of tobaco-smoke through the nostrils was carefully observed during rhinoscopic examination

The results of these observations show that in normal noses during quiet inspiration the powder impinges on the septum about half an inch within the nostrils and a third of an inch above the floor, and is then carried upwards and backwards in a broad band into the middle and superior meatus, entirely missing the inferior passage and lower turbinate. After deep and forcible inspiration the powder takes the same course and is, in addition, seen to be deposited round the upper part of the posterior choanæ, the upper fourth of the septum, and on the roof of the post-nasal space. It is also carried down the middle of the posterior wall of the oro-pharynx, coming to a point about the centre, from which spot it takes a straight course into the larynx, impinging on the arytenoids but missing the epiglottis. In expiration the smoke when gently exhaled passes chiefly through the inferior meatus-that is, below the upper level of the inferior turbinate. In forcible exhalation some smoke passes through the middle meatus as well as the lower.

In abnormal nares any irregularities, such as spurs, devia tions, enlargements, and hypertrophies of the inferior turbinated bodies, \&c., which prevent the passage of air from the restibule to the middle meatus will become covered with powder and divert its course in a manner varying with the exact position and extent of the irregularity. Most spurs and enlargements of the inferior turbinate are situated too low to intercept the inspired powder; deviation of the septum, polypi, and enlargements of the middle turbinate, on the other hand, become thickly coated with powder. In expiration complete blocking of the inferior meatus diverts the smoke into the middle meatus, from which it issues slowly and diffusely instead of in a straight compact stream as seen when it comes through the inferior meatus in a normal nose. Spurs, as a rule, split the stream, so that some comes below it through the inferior meatus and some above it through the middle passage, in which case they apparently cause no difficulty to expiration.

In cases of adenoid hypertrophy where the growth is slight the powder takes the usual course in the anterior nares, but collects between the septum and the growths and around the posterior choanæ. In bad cases the powder takes a lower course than in a normal nose, being seen resting chiefly on the inner and upper surfaces of the inferior turbinate and on the lower part of the septum. Expiration is not as a rule interfered with. In no case of either normal or abnorma nares was any powder seen on the under surface of the lower turbinate or along the floor of the nose.

From these observations it may be gathered that during quiet inspiration in a normal nose the air traverses the middle, the superior, and probably the fourth meatus, and never the inferior meatus. This makes it a little difficult to explain how the inferior turbinates perform their function of warming and moistening the air, but render the stimulation of the olfactory nerve endings easily explicable. As regards spurs and deviations of the septum and enlargements of the inferior turbinates it seems that they only interfere with inspiration when they are in the way of the entrance of air into the middle meatus. Polypi or enlargements of the middle turbinates, on the contrary, considerably interfere with easy inspiration. Hypertrophies and growths springing from the roof of the naso-pharynx will also cause considerable obstruction to inspiration, being in the direct air way. It 
may also be concluded that in expiration the air traverses the inferior meatus chiefly and that any hypertrophies or deformities causing stenosis of this passage will render expiration uncomfortable and difficult. In conclusion. it may be noted that the use of lycopodium as above described may be applied for practical purposes. The powder will be freely deposited on any irregularity which is causing obstruction and which should be removed, and, conversely, if a spur, for example, is left untouched by the powder it may be left alone as far as respiration is concerned, unless it is sufficiently large to interfere with expiration, which is not often the case.

Harley-street, W.

\section{d ithirror}

\section{HOSPITAL PRACTICE, BRITISH AND FOREIGN.}

Nulla autem est alia pro certo noscendi via, nisi quamplurimas et norborum et dissectionum historias, tum aliorum tum proprias collectas habere, et inter se comparare.-MoRGaGNI De Sed. et Caus. Morb., lib. iv., Proœmium.

\section{ST. GEORGE'S HOSPITAL.}

A CASE OF H AMMORRHAGIC TYPHOID FEVER.

(Under the care of Dr. W. EWART.)

Fon the notes of the case we are indebted to Dr. Lee Dickinson.

A woman, aged 29 years, was admitted into St. George's Hospital on Nov. 18th, 1892, under the care of Dr. Ewart. The family history was good and there was nothing upon the most careful inquiry that could be construed into inheritance of hæmophilia. The patient, indeed, had been liable to isomewhat profuse menstruation for the last seven years, but there were no other hrmorrhages and the general health was fairly good. The only serious illness remembered was an attack of pleurisy on each side in succession in 1886; the left pleura was aspirated and she made a good recovery. "There was no suspicion of alcoholism.

The patient was sent to the hospital as a case of typhoid rever of about 12 days' duration, the leading symptoms having been head-ache, perspirations, and disturbed sleep. Spots had been found four days before admission. When the patient was admitted she was somewhat anæmic and rather too fat, but she was not profoundly impressed by her illness, and there seemed to be no reason why she should not make a good recovery. The diagnosis of typhoid fever was fully confirmed. There were several rose-spots on the abdomen at the time of admission and a few spots were observed as late as Dec. 7th. The bowels were at first confined. The temperature was irregular but never very high ; it reached $103^{\circ} \mathrm{F}$. on more than one occasion and averaged about two degrees lower. As regards the hæmorrhages, the first to be observed was a moderate loss per vaginam, which was present on admission and continued to within a week of death. Early on Dec. 12th severe hæmorrhage from the gums set in and later in the day a copious motion was passed consisting largely of red blood. Saccharated lime, gallic acid, and the msual remedies for intestinal hæmorrhage were employed, but blood continued to pass from the bowel, though not in large quantity. Many small petechiæ appeared on the skin, a considerable ecchymosis under the right eye, and others beneath the ocular conjunctiva. On Dec. 15th the urine was loaded with corpuscular blood, the vaginal discharge having ceased. "The retinæ were free from hæmorrhage. A drop of blood from the finger Howed readily, clotted very imperfectly, and was of pink colour. Microscopically it resembled the blood of pernicious anæmia, the red cells being enormously diminished in number and individually rich in hæmoglobin. The leucocytes were considerably increased, and on one or two occasions granular masses of pigment were seen. The first copious hæmorrhage from the bowel was followed by a rise of pulse-rate from 112 to 140 and a general change for the worse in the patient; it had been apparent, however, for some days that the weakness was greater and the anæmia more intense than so mild an attack of typhoid fever would itself account for. Eventually she became extremely Blanched and died from exhaustion on Dec. 18th.
Necropsy. - At the post-mortem examination, which was made by Dr. H. D. Rolleston, the blood was found to be generally fluid though the cavities of the heart contained pale clots. The pleural cavities were closed by old adhesions, but the pericardium and peritoneum showed numerous petechir, and beneath the endocardium of the right auricle was an extensive hæmorrhage. Hæmorrbages were found also under the capsules of the liver and spleen, under the mucous coats of the bladder and stomach, in the pelves of both kidneys, and in the right Fallopian tube. In the ileo-cæcal region there were many ulcers, some of which were not far from perforation. These ulcers were undoubtedly of typhoid origin, though the edges were less infiltrated and undermined than usual. 'The colon and rectum were vividly injected but were not ulcerated.

Remarks by Dr. LEE DiCKINSON.-In THE LANCET of April 20th, 1901, p. 1156, there is an interesting annotation upon a paper by Dr. A. E. Eshner and Dr. T. H. Weisenberg. in the American Journal of the Medical Soiences for March on Hæmorrhagic 'Typhoid Fever. The paper describes two cases of this exceedingly rare complication of typhoid fever, and the annotation sugoests that alcchol, to which both the patients were addicted, was an important contributory cause of the hæmorrhagic condition. The above case may therefore be of interest, for it was a marked example of hæmorrhagic typhoid fever and one, moreover, into which the alcoholic factor did not enter. It seems equally certain that true hæmophilia may be excluded in so far as the term "hæmophilia" connotes a congenital tendency to hæmorrhage; but that many and various hıemorrhages took place and that they were in some way connected with the typhoid fever and directly dependent upon deficient coagulability of the blood is beyond all question.

The case occurred nearly nine years ago, since when certain therapeutic advances have been made in the direction of promoting the coagulative power of the blood when deficient, but whether the administration of any such substances as calcium chloride, nucleo-proteid, gelatin, and the like can be of material use when, as seems probable, the cause of the hæmorrhagic condition is a toxin in the blood may well te held as doubtful. In the future we may perhaps look more hopefully to some form of antitoxin treatment which will so far surpass the treatment at present in vogne for the prevention of typhoid fever as to neutralise at once the establisher disease and the general tendency to hæmorrhage, which is one of its rarest and most terrible dangers. Although the case is barren as regards therapeutic suggestion it seems to the point on the present occasion, and for this reason I venture to submit it to the profession. I am indebted to $\mathrm{Dr}$. Ewart for kindly allowing me to make use of the clinical records of the above case for which, as medical registrar at the time, I am entirely responsible.

\section{SOUTH DEVON AND EAST CORNWALI. HOSPITAL.}

\section{A SUCCESSFUL CASE OF LAPAROTOMY FOR} INTUSSUSCEPTION.

(Under the care of Mr. C. WHIPPLE.)

THE value of early operation in intussusception is now generally acknowledged, and the increasing number of cases recorded confirms it. If we were to judge of the mortality after the operation by the cases published a decidedly erroneous opinion would be formed, for in this as in most other operations a larger proportion of the successful than of the unsuccessful cases find their way into print. If we take all the cases in a large hospital in which an operation is performed for intussusception we find a death-rate which is decidedly higher than that based on recorded cases. The mortality after operation need not deter us from operating; though it should impress on us the need of early operation, for the death-rate increases with the duration of the invagination.

A girl, aged two years, was admitted into the South Devon and East Cornwall Hospital on May 30th, 1901, for vomiting and abdominal pain. The history of the case was that she had been suffering from "ulcerated bowels" for the previous fortnight. On May 29th, about 9 P. M., the child was attacked with sudden acute abdominal pain; she cried a good deal and vomited. On the 30 th, about 3 A.M., the bowels acted, the motion being dark and slimy, "like tar." The patient 